\title{
New species of Eclipta from the Brazilian Atlantic Rainforest (Coleoptera, Cerambycidae, Cerambycinae, Rhinotragini)
}

\author{
Francisco E. de L. Nascimento' \& Antonio Santos-Silva²
}

\begin{abstract}
1. Laboratório de Entomologia, Departamento de Zoologia, Universidade Federal do Rio de Janeiro, Rio de Janeiro, RJ, Brazil. (eribnascimentofi@gmail.com) 2. Museu de Zoologia, Universidade de São Paulo, São Paulo, SP, Brazil. (toncriss@uol.com.br)
\end{abstract}

Received 7 December 2016

Accepted 8 May 2017

DOI: $10.1590 / 1678-4766 e 2017027$

ABSTRACT. In this work, a new species of cerambycid beetles is described and illustrated: Eclipta dendensis sp. nov., from the state of Bahia, Brazil.

KEYWORDS. Neotropical Region, South America, taxonomy.

According to MonNé (2016), Eclipta Bates, 1873 includes 58 species distributed from Mexico to southern South America. Bates (1873) divided Ommata White, 1855 in 3 groups of species, based primarily on the shape of the legs. The first group included the species with "Legs long and slender; middle femora gradually and moderately clavate". This group included 4 subgroups, characterized by the elytral shape: Phoenissa, Chrysaethe, Ommata, and Rhopalessa. The second group included the species with "Legs slender; middle femora abruptly but not very broadly clavate; elytra with sides subparallel, apex truncated". Finally, the third group included species with "Legs robust; middle femora abruptly and very thickly clavate; first joint of hind tarsi greatly elongated; elytra entire", that included only Agaone Pascoe, 1859. Currently, Chrysaethe, Ommata, Rhopalessa, Eclipta, Phoenissa (= Oregostoma Audinet-Serville, 1833) and Agaone are considered distinct genera. Notwithstanding, the division between "legs long and slender" and "legs long" is completely subjective and not true and we see the species allocated in each group by BATES (1873). For example, the legs in Ommata (Eclipta) eirene (Newman, 1841) (currently, Eclipta eirene), are long and slender, exactly as in Ommata (Chrysaethe) beltiana Bates, 1872 (currently, Chrysaethe beltiana). In the same way, the difference in the shape of mesofemora is not true, and it is very variable in the species currently placed in Eclipta (even in species originally placed in this genus by BATES, 1873) and Chrysaethe.

As Eclipta and Chrysaethe have the elytral apex truncate, and the elytra is very variable in the species placed in Eclipta by BATES (1873), it is absolutely impossible to separate these genera based on the features originally included. However, the type species of each genus, designated by PeñaherRera-LeIva \& TAVAKILIAN (2004), allow separating them (notably by the pronotal shape), although it would be necessary a complete revision of these genera to correctly place each species currently in them.

The new species agrees moderately well with the type species of Eclipta [Ommata (Eclipta) flavicollis Bates, 1873], mainly by the antennal, pronotal, elytral and legs shape. Thus, we are describing it in Eclipta.

\section{MATERIAL AND METHODS}

Photographs were taken in the MZSP with macro lens, controlled by Zerene Stacker AutoMontage software. Measurements were taken in " $\mathrm{mm}$ " using an ocular micrometer and stereomicroscope, was also used in the study of the specimen.

The acronyms used in the text are: MZFS, Museu de Zoologia da Universidade Estadual de Feira de Santana, Bahia, Brazil; MZSP, Museu de Zoologia, Universidade de São Paulo, São Paulo, Brazil.

\section{RESULTS AND DISCUSSION}

\section{Eclipta dendensis sp. nov.}

(Figs 1-4)

urn:lsid:zoobank.org:pub:0955960C-B4BA-452D-93011BD0E13A69B6

Female. Integument black with greenish or violaceous reflections on some areas; antennomere VIII with dark reddish-brown ring on basal quarter; antennomere IX with reddish-brown ring on basal quarter, more yellowish ventrally; antennomeres X-XI with pale yellow ring on basal 
third; pronotum yellow except transverse reddish-brown band close to distal margin; sides of prothorax mostly yellow except black area close to procoxal cavity, reddish-brown basal area and black distal area, and irregular reddish-brown macula on distal third; elytra with small reddish macula on sides of humeri; metacoxae brown maculated with reddishbrown areas; metatrochanters yellowish-brown; distal 2/3 of metatarsomere I and entire surface of II pale yellow; metatarsomere III reddish-brown on basal half, brown on lobes; metatarsomere IV reddish-brown; basal half of metatarsomere $\mathrm{V}$ reddish-brown, distal half dark brown; basal projection of abdominal ventrite I pale yellow.

Head (Fig. 4). Rostrum (between apex of inferior ocular lobe and genal apex) in frontal view 0.8 time length of lower eye lobe. Frons finely, abundantly punctate close to clypeal area and lower eye lobes, somewhat coarser, sparser on inverted V-shaped central area; with short, decumbent, sparse yellowish setae, distinctly more abundant close to lower eye lobes. Area between lower eye lobes finely, abundantly punctate (punctures as on frontal area close to lower eye lobes); with short, decumbent, moderately abundant yellowish setae close to eyes, sparser toward coronal suture, interspersed with long, erect, sparse yellowish setae close to eyes. Area between antennal tubercles and prothoracic margin moderately coarsely, densely, confluently punctate; with minute, decumbent, sparse yellowish setae interspersed with long, erect yellowish setae. Antennal tubercles gradually minutely punctate toward apex; with short, erect, moderately sparse yellowish setae. Coronal suture distinct from clypeus to area between antennal tubercles. Postclypeal area finely punctate basally, smooth toward apex; with short, decumbent, sparse yellowish setae on punctate area, interspersed with long, erect yellowish setae, glabrous on smooth area. Labrum minutely, abundantly punctate basally, smooth toward apex; with long, erect, yellowish setae laterally and brush of yellowish setae on distal margin. Outer side of mandibles, moderately finely, abundantly punctate on basal 2/3 (punctures, confluent and oblong); with some long, erect yellowish setae. Area behind lower eye lobes with short, decumbent yellowish setae close to eye; remaining surface with long, erect, sparse yellowish setae. Genae finely, moderately sparsely punctate toward ventral side, finely, densely punctate toward dorsal side (somewhat striate close to eye), smooth toward apex; with minute, decumbent, sparse yellowish setae, ventrally interspersed with some long, erect yellowish setae. Gular region smooth close to prothorax, finely, sparsely punctate toward submentum; glabrous close to prothorax, with short and long, erect, sparse yellowish setae toward submentum. Submentum finely striate-punctate; with short and long, erect, moderately sparse yellowish setae. Distance between upper eye lobes 0.65 times length of scape; distance between lower eye lobes in frontal view 0.55 time length of scape. Antennae 1.2 time elytral length, reaching distal fifth of elytra; ventral side of scape, pedicel and antennomeres III-VII with long, erect, thick, dark setae, gradually shorter, sparser toward VII; antennal formula (ratio) based on antennomere III: scape $=0.82$; pedicel $=0.29$; IV
$=0.70 ; \mathrm{V}=0.88 ; \mathrm{VI}=0.76 ; \mathrm{VII}=0.70 ; \mathrm{VIII}=0.59 ; \mathrm{IX}=$ $0.50 ; \mathrm{X}=0.50 ; \mathrm{XI}=0.67$.

Thorax. Prothorax subcylindrical, 1.2 time longer than wide, laterally slightly rounded. Pronotum coarsely punctatereticulate; with long, erect, moderately abundant yellowish setae; with slightly conspicuous yellowish-white pubescence basally. Sides of prothorax coarsely, abundantly punctate on yellowish area, obliquely striate on basal reddish-brown area, smoother on distal black area; with yellowish-white pubescence on basal half of yellow area; with short and long, erect yellowish except subglabrous distal area. Prosternum coarsely, abundantly punctate on basal half, mostly smooth on distal half; with whitish pubescence interspersed with long, erect, whitish setae on punctate area, glabrous on smooth area. Prosternal process narrowed centrally, notably triangularly expanded toward apex; triangular depressed, centrally carinate. Mesosternum centrally with whitish pubescence not obscuring integument, laterally slightly conspicuous. Mesepisternum, mesepimeron and metepisternum with whitish pubescence partially obscuring integument, interspersed with long, erect whitish setae. Metasternum minutely, densely punctate (less dense toward central smooth area), laterally interspersed with fine, moderately abundant punctures; with whitish pubescence, gradually sparser toward center, interspersed with long, erect whitish setae. Scutellum longitudinally sulcate centrally, mainly after midlength; with minute whitish setae not obscuring integument. Elytra. Reaching apex of fourth abdominal segment (Fig. 1); outer sides convergent from base to slightly after apex of basal third, parallel-sided toward apex; apex slightly obliquely truncate, with minute projection at sutural angle; coarsely, punctate-reticulate throughout; with minute, moderately abundant yellowish setae interspersed with long, erect yellowish setae (longer, more abundant on basal third). Legs. Apex of metafemora surpassing elytral apex (Fig. 3). Metatarsomere I 1.45 time II-III together.

Abdomen (Fig. 2). Ventrite I minutely, densely punctate laterally, interspersed with fine punctures, smooth centrally; ventrites II-IV minutely, densely punctate interspersed with fine punctures, except smooth centerdistal area; ventrite $\mathrm{V}$ minutely, minutely, densely punctate interspersed with fine punctures, except smooth basal region; laterally with whitish, decumbent, abundant whitish setae (not obscuring integument), interspersed with long, erect whitish setae, gradually sparser toward center (glabrous on center-distal area of ventrite I and basal quarter of V); apex of ventrite $\mathrm{V}$ rounded.

Dimensions in mm (holotype female). Total length (from mandibular apex to abdominal apex), 8.55; prothorax: length, 1.75; basal width, 1.26; distal width, 1.25; widest prothoracic width, 1.45; humeral width, 1.60 ; elytral length, 5.00 .

Type material. Holotype $q$ from BRAZIL, Bahia: Igrapiúna (Reserva Ecológica da Michelin, Pacangê; 1350'16.0”'S / 39¹4'28.9”W; 139 m), 21-22.V.2012, M. Aragão, E. Menezes \& E. Mota col. (MZSP). 

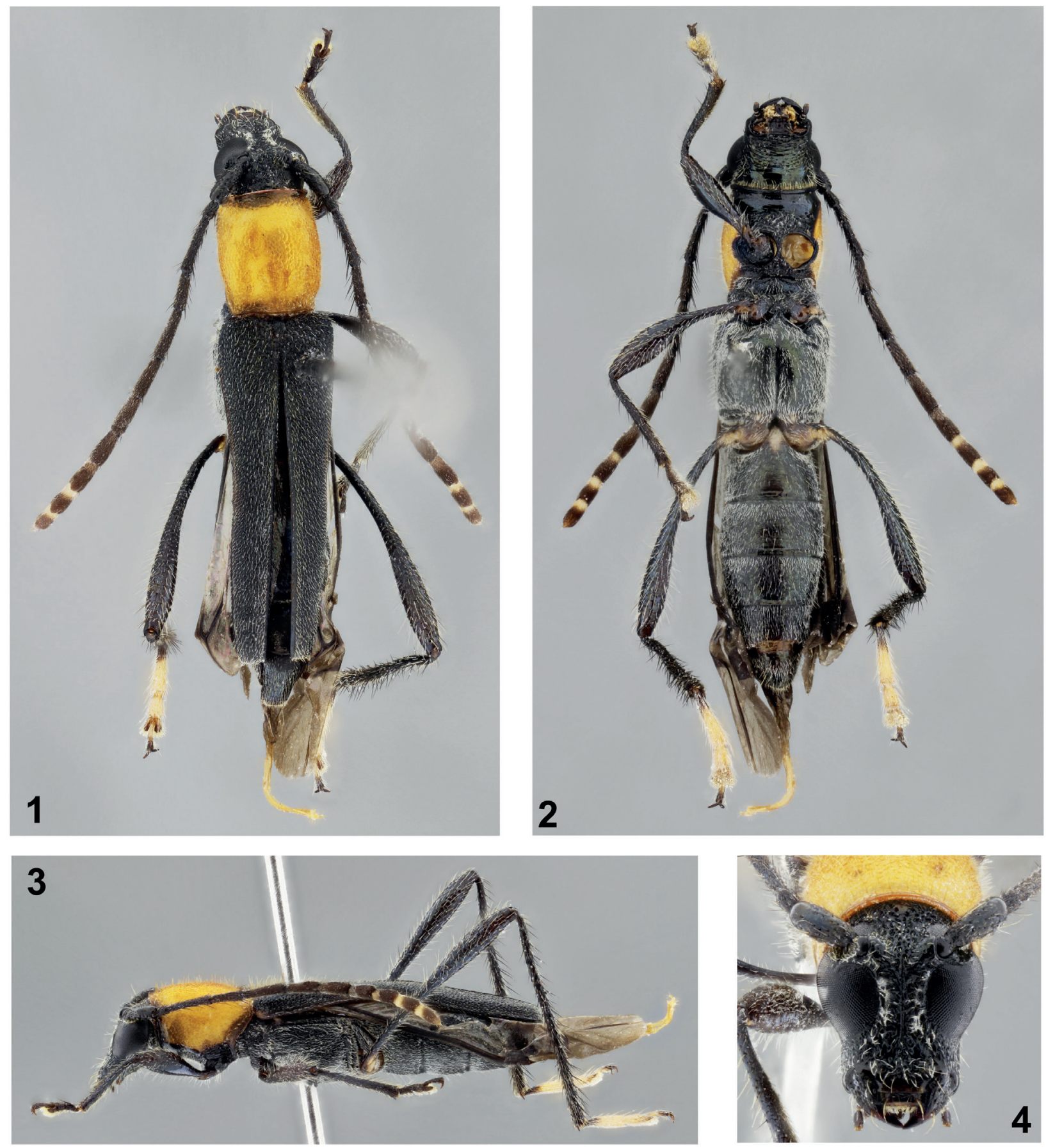

Figs 1-4. Eclipta dendensis sp. nov., holotype female, habitus: 1, dorsal; 2, ventral; 3, lateral; 4, frontal view.

Etymology. The name refers to the region where the holotype was collected, popularly known as Costa do Dendê.

Remarks. Eclipta dendensis sp. nov. resembles E. eirene (Newman, 1841) by the metatarsi mostly pale yellow, but differs as follows (female): distal antennomeres with basal light ring; pronotum coarsely punctate-reticulate; distal $2 / 3$ of outer side of the elytra parallel-sided; sutural distal third of the elytra not dehiscent; elytra not narrowed toward apex from midlength; apex of metafemora slightly surpassing elytral apex; elytral apex reaching apex of fourth abdominal segment. In E. eirene, the distal antennomeres are not ringed, pronotum is moderately finely and abundantly punctate, the distal $2 / 3$ of outer side of the elytra is somewhat concave, distal third of the sutural angle of the elytra is dehiscent, elytra narrowed toward apex from midlength, apex of metafemora distinctly surpasses the elytral apex, and elytral apex reaching at about midlength of third 
abdominal segment (sometimes the apex of third segment). It differs from $E$. thoracica (Bates, 1873), but differs mainly by the metatarsi mostly pale yellow (dark in E. thoracica).

Acknowledgments. The authors are grateful to Dr. Kevin Flasher, manager in the Bahia's plantations Michelin Ltda., for all support; to Dr. Sergio Ricardo Andena (MZFS) and Marcos Aragão (MZFS) for the assistance and fieldwork.

\section{REFERENCES}

Bates, H. W. 1873. Notes on the longicorn Coleoptera of tropical America. The Annals and Magazine of Natural History 11(4):21-45.

Monné, M. A. 2016. Catalogue of the Cerambycidae (Coleoptera) of the Neotropical Region. Part I. Subfamily Cerambycinae. Available at $<$ http://www.cerambyxcat.com/ > . Accessed on 10 Oct 2016.

Peñaherrera-Leiva, A. Y. \& Tavakilian, G. L. 2004. Nouvelles espèces et nouveaux genres de Rhinotragini (Coleoptera, Cerambycidae). III. Coléoptères 10(10):119-150. 